\title{
Serendipitous Detection of Cervical Nodal Metastasis in Glomus Jugulare
}

\author{
Shruti Venkitachalam ${ }^{1}$ Rayappa Chinnusamy ${ }^{1} \quad$ Narendranath Ashok ${ }^{1} \quad$ Swatee Vasant Halbe ${ }^{2}$ \\ ${ }^{1}$ Department of ENT, Head, Neck and Skull base Surgery, Apollo \\ Specialty Hospital, Chennai, Tamil Nadu, India \\ 2Department of Interventional Radiology, Apollo Specialty Hospital, \\ Vanagaram, Chennai, Tamil Nadu, India

\begin{abstract}
Address for correspondence Shruti Venkitachalam, MS (ENT), DNB (ENT), PDF, Department of ENT, Head, Neck and Skull Base Surgery, Apollo Specialty Hospital, Cenotaph Road, Teynampet, Chennai 600035, Tamil Nadu, India (e-mail: shruti.venkitachalam@gmail.com).
\end{abstract}

Indian J Neurosurg 2018;7:256-259
Abstract
Keywords
- metastatic glomus
- glomus in cervical nodes
- carotid angiogram in metastatic glomus

We present the case of a 50 -year-old man who presented to us with a history of having received radiation therapy for a glomus jugulare tumor. He had been on regular follow-up with serial imaging scans. The MRI done after 4 years of treatment revealed an interval increase in size. Carotid angiogram revealed, in addition to the glomus, multiple lymph nodes of similar pattern of vascularity, well lateral to the carotid sheath, in the ipsilateral neck. He underwent resection of the tumor and a neck dissection. Histopathology confirmed metastatic glomus jugulare in the cervical lymph nodes. He received adjuvant radiotherapy and is doing well.
Paragangliomas of head and neck, also known as chemodectomas or glomus tumors, are masses arising from chemoreceptor cells of the neuroendocrine system. They are rare tumors, comprising $0.6 \%$ of head and neck masses. The most common are those arising from the carotid body, whereas they may also arise from chemoreceptor cells associated with vagus nerve (glomus vagale), jugular bulb (glomus jugulare), middle ear (glomus tympanicum), and other rare sites such as the larynx and pharynx. A very small subset of these demonstrate malignant behavior by metastasizing to various sites, incidence of this being $0.016 \%{ }^{1}$

We report the case of a man with glomus jugulare, who had been treated with radiotherapy, who presented to us with recurrence in the jugular foramen and multiple metastatic cervical lymph nodes.

\section{Case Report}

A 50-year-old man presented with tinnitus in the right ear since 9 months and slurring of speech, difficulty in swallowing, and occasional right-sided neck pain since 3 months. He had two episodes of right-sided facial weakness with spontaneous resolution in 5 years, preceding the time of presentation. The patient had received radiotherapy of 21Gy in three fractions to the right jugular foramen tumor by cyber knife technique. He was on regular follow-up with serial magnetic resonance imaging (MRI) scans, which showed no progression in the size of tumor, until about 4 years later (-Fig. 1).

Examination revealed right hypoglossal nerve weakness, and a pinkish hue was noted in relation to right hypotympanum, through an intact tympanic membrane.

Carotid angiogram done for the purpose of embolization preoperatively revealed a highly vascular tumor in the right petrous region consistent with glomus jugulare, supplied by multiple feeders from ascending pharyngeal, occipital, and internal maxillary arteries. Three vascular tumors were detected in the right neck, located posterolateral to the internal carotid artery, and solely supplied by the occipital artery (-Fig. 2). All four tumors were embolized with poly vinyl alcohol sponge particles.

Postembolization, excision of the glomus jugulare tumor was done by Fisch's infratemporal fossa type A approach along with clearance of right level II lymph nodes ( - Fig. 3 ).

Histopathologic examination revealed fibrocollagenous tissue with bony fragments infiltrated by a neoplasm composed of nests and islands of round to polygonal cells separated by thin fibrovascular septae suggestive of paraganglioma. Examination of the lymph nodes revealed metastatic tumor with perinodal extension in 5 out of 16 lymph nodes (-Fig. 4).

In view of this histopathology report, the patient underwent comprehensive neck dissection. Pathologic examination showed all lymph nodes to be free of tumor.
License terms

Society of India received

June 5, 2017

Accepted after revision

October 24, 2017

published online

April 10, 2018
DOI https://doi.org/

10.1055/s-0038-1639383. ISSN 2277-954X. 

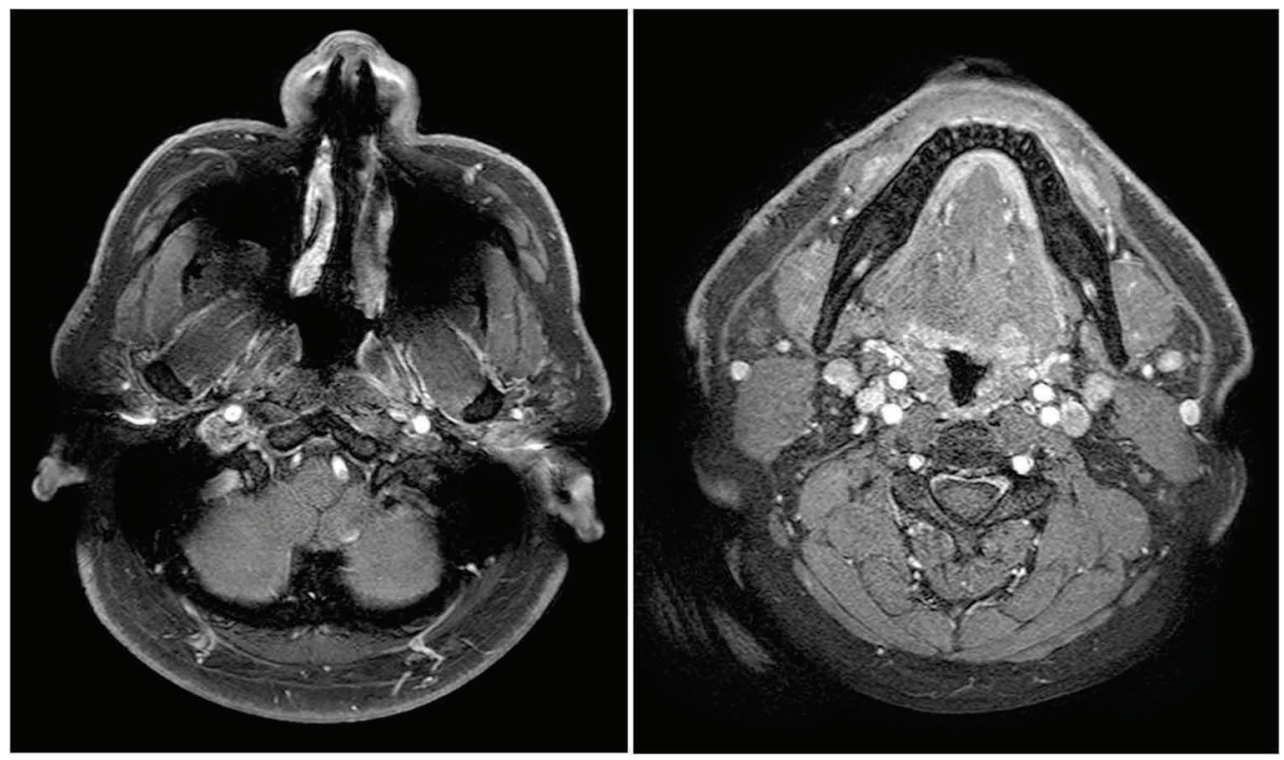

Fig. 1 (Left panel) Preoperative MRI showing recurrent lesion in relation to right jugular bulb. (Right panel) MRI evidencing bilateral cervical nodes that did not appear suspicious therein. The nature of the right level II node was revealed only on the carotid angiogram. MRI, magnetic resonance imaging.

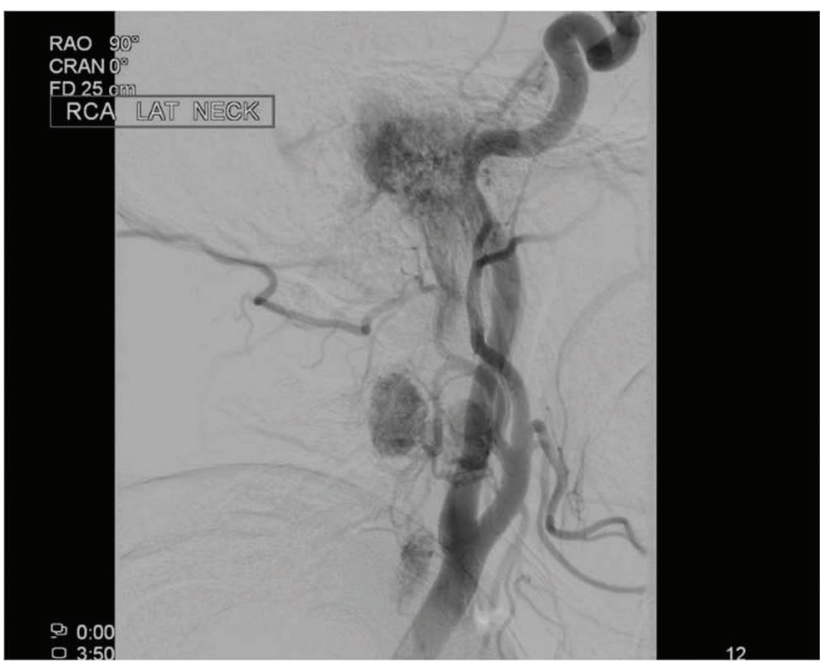

Fig. 2 Right carotid angiogram showing presence of recurrent tumor at skull base and multiple cervical lymph nodal metastases.

External beam radiotherapy of a total dose of $54 \mathrm{~Gy}$ in 30 fractions, by image-guided technique, was delivered to the neck.

He has been on regular follow-up since then and has no evidence of locoregional recurrence.

\section{Discussion}

Glomus jugulare is a slow-growing, benign tumor that may turn locally aggressive, but metastasis is very rare. The first report of a glomus jugulare was published in 1945 . $^{2}$

Glomus jugulares are benign tumors arising from paraganglionic tissue of jugular bulb. ${ }^{2}$ Paragangliomas constitute less than $0.5 \%$ of tumors of the head and neck region. ${ }^{3}$ Paraganglionic tissue is widely dispersed in extra-adrenal neuroendocrine system along the great vessels and nerves. ${ }^{3,4}$

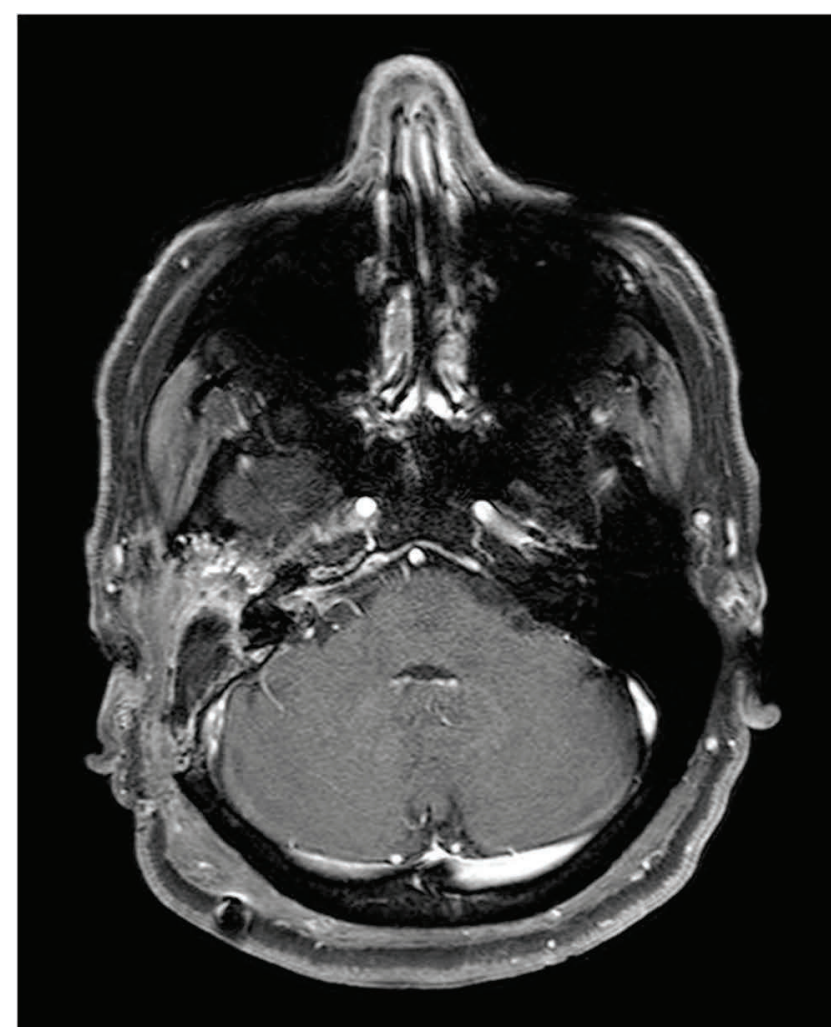

Fig. 3 Postoperative MRI. MRI, magnetic resonance imaging.

Paragangliomas are classified into sympathetic secretory (5\%, mainly arising from the thorax, abdomen, and pelvis) and parasympathetic nonsecretory (95\%, mainly arising from the head and neck region ). ${ }^{3}$ In the head and neck region, they are particularly associated with the parasympathetic nervous system, especially along glossopharyngeal and vagus nerves and their branches. Accumulation of these tissues is called glomus bodies, largest of these being the carotid bodies that have a chemoreceptor function. ${ }^{4}$ 


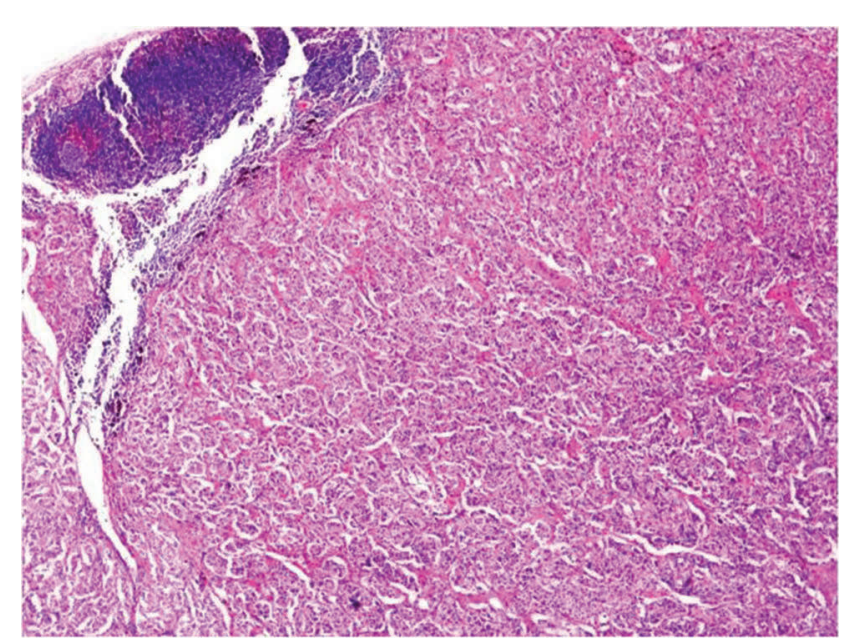

Fig. 4 Photomicrograph of a level II cervical lymph node showing features of paraganglioma.

Glomus jugulare are the most common benign tumors of temporal bone. ${ }^{2}$ The jugulotympanic glomus tumors could possibly arise from paraganglia along glossopharyngeal nerve (Jacobson's nerve) or auricular branch of Vagus nerve (Arnold's nerve). ${ }^{4}$ Their growth is typically extremely slow. A glomus jugulare patient surviving untreated for 60 years has been reported. ${ }^{5}$-Table 1 summarizes the representative literature in various aspects of these studies performed hitherto.

These tumors present most commonly in females. They commonly present in fifth decade of life. ${ }^{4}$ Symptoms vary depending on the structures involved and pattern of spread and may include deafness, tinnitus, vertigo, otalgia, hemorrhage, discharge, headache, and symptoms attributable to lower cranial nerve palsies. ${ }^{2,4}$ These tumors may occasionally secrete vasoactive substances. ${ }^{6}$

There are various classifications of these tumors for the purpose of comparative studies. Glomus jugulares have been classified into four types by Ugo Fisch. Type A tumors are localized to middle ear (glomus tympanicum). Type B tumors are limited to tympanomastoid area without destruction of bone in the infralabyrinthine compartment of the temporal bone. Type C tumors are those extending and destroying bone of the infralabyrinthine and apical compartment of the temporal bone. Type $\mathrm{D}$ glomus jugulars are ones with intracranial extension. ${ }^{2}$

Various imaging modalities have been utilized for glomus tumors. MRI seems to be superior to computer tomography (CT), with increased signal intensities on T2-weighted images being characteristic but not diagnostic of the lesion. ${ }^{3}$ On MRI these lesions may have a "salt and pepper" appearance, the "salt" being areas of high signal foci on T1WI within the tumor due to hemorrhage or slow-flow vessels on T2WI. The "pepper" areas are low T1 and T2 signal flow voids within tumor vessels with high-velocity flow. ${ }^{1}$

Digital subtraction angiography (DSA) may reveal feeding vessels from the external and internal carotid systems. ${ }^{1}$

Functional imaging could be helpful in detecting occult paragangliomas. $^{3}$

${ }^{68}$ Gadolinium-labeled Dotanoc positron emission tomography-computed tomography (PET-CT) has been shown to be useful for baseline evaluation of head and neck paragangliomas for detection of synchronous lesions and distant metastases.?

There are no local imaging findings that can differentiate a malignant from a benign paraganglioma. ${ }^{1}$

Local invasiveness is common; however, malignant transformation is rare. Metastasis, which defines presence of malignancy, is very rare, with a reported incidence of 1 to $4 \%{ }^{2}$ However, this could be an overestimate due to preferential reporting of metastatic tumors and due to occurrence of multicentric tumors. ${ }^{2}$

A review of literature on metastatic glomus jugulares revealed 100 sites of metastasis in 53 case reports. It concluded that the most common sites of metastases are the lungs, cervical lymph nodes, vertebrae, ribs, and liver and that these could present after 30 years of initial treatment. There was no difference in age and sex distribution amongst metastatic and nonmetastatic glomus jugulares. There was a higher incidence of pain and lower incidence of hearing loss

Table 1 Relevant literature on clinical feature, evaluation, and management of metastatic glomus jugulare

\begin{tabular}{|l|l|l|}
\hline Author & Year & Contribution \\
\hline Brewis et al $^{2}$ & 2000 & $\begin{array}{l}\text { Glomus jugulare with metastases are an aggressive subset of these tumors, with } \\
\text { shorter time to presentation and progression }\end{array}$ \\
\hline Pipas and Krywicki $^{15}$ & 2000 & First reported use of gemcitabine in progressive metastatic glomus jugulare \\
\hline Boedeker et al ${ }^{12}$ & 2007 & $\begin{array}{l}\text { SDHB mutations associated with a high risk of malignancy in head and neck } \\
\text { paragangliomas }\end{array}$ \\
\hline Kamoshima et al ${ }^{13}$ & 2008 & $\begin{array}{l}\text { Case report of craniocervical paraganglioma with multiple pulmonary metastases at } \\
\text { presentation. Proposed that local control of primary by resection could curb progres- } \\
\text { sion of metastatic foci }\end{array}$ \\
\hline Chapman et al ${ }^{1}$ & 2013 & $\begin{array}{l}\text { Pain, neck mass, and younger age of presentation could point toward malignancy in } \\
\text { paragangliomas }\end{array}$ \\
\hline Sharma et al ${ }^{7}$ & 2016 & $\begin{array}{l}\text { 68Ga-Dotanoc PET-CT as a baseline imaging modality useful in characterizing head and } \\
\text { neck paragangliomas and detecting synchronous tumors }\end{array}$ \\
\hline Jain et al ${ }^{16}$ & $\begin{array}{l}\text { Presented an interesting image of }{ }^{68} \text { Ga-Dotanoc PET-CT detecting somatostatin } \\
\text { receptor expressing lesion in the jugular bulb with extension to the sigmoid sinus, } \\
\text { with a metastatic lesion in the sacrum }\end{array}$ \\
\hline
\end{tabular}

Abbreviation: Ga, gadolinium; PET-CT, positron emission tomography-computed tomography; SDHB, succinate dehydrogenase subunit B 
in metastatic tumors. ${ }^{4}$ Metastases is also more common in extra-adrenal sympathetic paragangliomas than in adrenal or parasympathetic paragangliomas. ${ }^{3}$

Glomus jugulares are essentially benign tumors. ${ }^{2}$ Paragangliomas have identical histopathologic appearance irrespective of the site. They are typically composed of polygonal chief cells arranged in nests (Zellballen) surrounded by a capillary network. Nuclei may show significant atypia, but this is not an indication of malignancy. Secondary changes such as stromal fibrosis and hemorrhage may be seen. ${ }^{8}$ Immunohistochemistry may reveal expression of neuroendocrine markers neuron-specific enolase, chromogranin, and synaptophysin in the chief cells. ${ }^{9}$ S100 could demonstrate the sustentacular cells that surround the nests of tumor cells. ${ }^{10}$

Prediction of malignancy on histopathologic examination alone could be difficult. Presence of increased mitosis, necrosis, vascular invasion, and decreased expression of neuropeptides could be probable markers of increased aggressive behavior. ${ }^{11}$ The only absolute criterion to define malignancy remains the presence of local and distant metastases. ${ }^{2}$ Histologically, it is difficult to differentiate benign and malignant glomus. However, presence of similar appearing tissue at a distant site accounts for metastases.

Three-fourths of paraganglioma syndromes (PGLs) have been associated with molecular genetic basis. PGL1 is associated with mutations of succinate dehydrogenase subunit D (SDSD) gene, PGL3 is caused by SDHC mutations, and PGL4 is caused by SDHB gene mutations. A significant number of head and neck paragangliomas are caused by these mutations. A screening of these patients for SDHB, SDHC, and SDHD mutations is recommended. SDHB mutations are associated with high risk of malignant transformation. In these patients, a three-body region imaging (including the head and neck, thorax, and abdomen) or F-dopa PET is recommended to rule out metastasis. ${ }^{12}$

The main modality of treatment remains surgery, radiotherapy, or a combination of both. ${ }^{4}$ However, the efficacy of radiotherapy and chemotherapy remains unclear. Although paragangliomas are known to be radioresistant, external beam radiotherapy could occasionally suppress their growth. Chemotherapy has been reported to be unsuccessful. ${ }^{13}$ Secreting paragangliomas need $\alpha$ - and $\beta$-adrenergic blockade prior to surgery. ${ }^{3}$

Radiopharmaceutical treatment such as I-mIBG (I-metaiodobenzylguanidine) either alone or in combination with chemotherapy has been tried in a few cases. ${ }^{3}$ Resection of the primary may halt the progression of pulmonary metastasis, possibly involving the immune system as seen in renal cell carcinomas. $^{14}$

Gemcitabine may have some role in treatment of progressive metastatic glomus jugulare. ${ }^{15}$

The metastatic glomus jugulare tumors are likely to be more aggressive, with a shorter time duration before presentation and higher rates of persistent or recurrent local disease and death. ${ }^{4}$ It is also suggested that presence of pain, rapidly enlarging neck mass, and younger age are predictive of malignancy and must point toward an aggressive diagnosis and management. ${ }^{1}$

\section{Conclusion}

Metastasis, synonymous with malignancy, is rare in glomus tumors. However, the clinical possibility of occult metastases must be considered in all glomus tumors. Imaging remains key in diagnosis, which is confirmed later by histopathologic examination. Surgical resection remains the treatment of choice. Role of adjuvant therapies is speculative.

\section{Funding \\ None.}

\section{Conflict of Interest \\ None.}

\section{References}

1 Chapman DB, Lippert D, Geer CP, et al. Clinical, histopathologic, and radiographic indicators of malignancy in head and neck paragangliomas. Otolaryngol Head Neck Surg 2010;143(4):531-537

2 Brewis C, Bottrill ID, Wharton SB, Moffat DA. Glomus jugulare tumour with metastases to cervical lymph nodes. J Laryngol Otol 2000;114(1):67-69

3 Yetişer S, Ramadan S. Multiple primary malignant paraganglioma of the head and neck with lymph node metastasis. Kulak Burun Bogaz Ihtis Derg 2015;25(4):232-236

4 Brewis C, Bottrill ID, Wharton SB, Moffat DA. Metastases from glomus jugulare tumours. J Laryngol Otol 2000; 114(1): 17-23

5 Brown JS. Glomus jugulare tumours. Methods and difficulties of diagnosis and surgical treatment. Laryngoscope 1967;77:765-787

6 Duke WW, Boshell BR, Soteres PCJ. A norepinephrine secreting glomus tumour presenting as a phaeochromocytoma. Ann Intern Med 1964;60:1040-1047

7 Sharma P, Thakar A, Suman KC S, et al. 68Ga-DOTANOC PET/CT for baseline evaluation of patients with head and neck paraganglioma. J Nucl Med 2013;54(6):841-847

8 Lack E. Diagnostic Surgical Pathology. 2nd ed. New York, NY: Raven Press; 1994

9 Kliewer KECA, Cochran AJ. A review of the histology, ultrastructure, immunohistology, and molecular biology of extra-adrenal paragangliomas. Arch Pathol Lab Med 1989; 113(11):1209-1218

10 Capella C, Riva C, Cornaggia M, Chiaravalli AMF, Frigerio B, Solcia E. Histopathology, cytology and cytochemistry of pheochromocytomas and paragangliomas including chemodectomas. Pathol Res Pract 1988;183(2):176-187

11 Linnoila RI, Lack EE, Steinberg SMKH, Keiser HR. Decreased expression of neuropeptides in malignant paragangliomas: an immunohistochemical study. Hum Pathol 1988;19(1):41-50

12 Boedeker CC, Neumann HPH, Maier W, Bausch B, Schipper J, Ridder GJ. Malignant head and neck paragangliomas in SDHB mutation carriers. Otolaryngol Head Neck Surg 2007;137(1):126-129

13 Kamoshima Y, Sawamura Y, Hokari M, Iwasaki Y, Akita H. Craniocervical paraganglioma with numerous pulmonary metastases-case report. Neurol Med Chir (Tokyo) 2008;48(9):401-404

14 Montie JE, Straffon RA, Deodhar SD, Barna B. In vitro assessment of cell-mediated immunity in patients with renal cell carcinoma. J Urol 1976;115(3):239-242

15 Pipas JM, Krywicki RF. Treatment of progressive metastatic glomus jugulare tumor (paraganglioma) with gemcitabine. Neuro-oncol 2000;2(3):190-191

16 Jain TK, Basher RK, Shukla J, Mittal BR, Panda NK. Malignant Jugular Paraganglioma: Unusual Presentation on 68Ga DOTANOC PET/CT. Clin Nucl Med 2016;41(2):150-152. 